is still much to be learned about how, and whether, the compound affects ageing in humans. These subtleties are all but impossible to fit into a television sound bite - a fact that allows the snake-oil salesmen to gain the upper hand.

David Sinclair, a molecular biologist at Harvard Medical School in Boston, Massachusetts, found that out the hard way. As a co-founder of Sirtris, Sinclair has had his work touted in magazines and newspapers, and has appeared on US national television sipping red wine and discussing resveratrol's effects. But he now finds that quotes and images from his many media appearances are being taken out of context and used to pitch commercial resveratrol supplements of dubious value. Sinclair has had to pay lawyers tens of thousands of dollars to send letters demanding that his name be stripped from such advertisements.

Adding to the problem is the poor regulation of the thousands of varieties of dietary supplements for sale in the United States. Going in the opposite direction from Europe, where supplements must be shown to be safe in both quantity and quality, Congress in 1994 passed the Dietary Supplement Health and Education Act, a bill that limited the ability of the Food and Drug Administration (FDA) to rein in the burgeoning industry. Safety and the accuracy of advertising claims were left to be policed largely by the manufacturers themselves.

In the absence of adequate regulation, false claims by supplement makers abound. At best, these claims can cheat consumers of their money. At worst, as in the case of ephedra, widely touted for weightloss, they could cost users their lives.

Since 1994, US lawmakers have repeatedly tried, and failed, to

improve oversight of the dietary-supplements industry. The latest attempt will make its way through Congress this year in the shape of the Dietary Supplement Safety Act of 2010, a set of amendments to the FDA's legislative charter put forward in February by Senators John McCain (Republican, Arizona) and Byron Dorgan (Democrat, North Dakota). The provisions would require dietary-supplement manufacturers to register with the Health and Human Services secretary, and would give the FDA authority to immediately recall supplements that are misbranded or that pose a health threat. Although

"Anything researchers say in the media must strike a careful balance between science, hope and hype." these provisions would not stop the sale of supplements that are a waste of money - a category that seems to include most or all of the anti-ageing elixirs - they are an important step forward, and Congress should approve them without delay.

Meanwhile, researchers should remain keenly aware of their responsibilities, especially in a field as fraught with anxiety and apprehension as ageing. Just as with stem cells or any other field with great medical promise but no clear timescale for delivery, anything they say in the media must strike a careful balance between science, hope and hype. Researchers must be honest with the public, and themselves, about what the science really is - what it can and cannot say, what it is and isn't likely to achieve (for example, allowing people to live forever) and what is still unknown. 'Let the buyer beware' may be a commercial maxim, but science can certainly reduce the risks.

\section{Content rules}

\section{Nature's new online commenting facility opens up the entire magazine for discussion.}

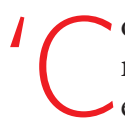
onversation is king', according to a mantra frequently repeated by enthusiasts of online social media. But we editors and writers tend to give our first allegiance to content - not least because of our labours to research, commission, select, create and otherwise add value to content, and to do so in a way that informs and stimulates our readers: the people who pay for it.

But, unquestionably, conversation can add value to such efforts. Therefore, this week we introduce an online commenting facility that will allow readers to respond directly to any of our content.

Commenting is not new to Nature. Our online news service (www.nature.com/news) has long allowed it, and recent examples show how lively and interesting readers' observations can be - in their response to our coverage of Google in China at go.nature.com/FJ6QTm, say, or of dismissed researchers in Mexico at go.nature.com/t75Zn7.

Online discussions about our research papers are likely to be considerably more subdued, according to the experience of other publishers who already allow commenting. This is understandable. Commenting on a paper in the rather formal context of a journal's website may seem daunting to some scientists, and to others may pose a needless risk of offending colleagues, or of making an unguarded statement that may come back to haunt them. Perhaps more importantly, a commenter acquires no formal academic credit for his or her efforts, making the time spent commenting seem like time wasted. For that reason, we will continue to publish formal responses to papers in our online Brief Communications Arising section, in which contributions are peer reviewed and have a high threshold for acceptance.

As for the acceptance thresholds for readers using the new commenting facility, we are adopting a twin-track approach. For News \& Views, Reviews and primary research, we will vet submitted items before they are allowed to appear on our site. Our intention is to remove only those submissions that are clearly subject to legal concern, obscenity or unjustified assertions. We will not seek to prohibit trivia, for example - although we'd be glad if our commenting readers could help keep the signal-to-noise ratio as high as our critically minded audience expects and deserves.

All other sections will be run on the same basis as online news is now: submitted comments will appear online immediately, without any monitoring or vetting beforehand. But they will be promptly removed on receipt of a substantive objection from a reader, on similar grounds to those above. People wishing to comment should be alert to the currently unavoidable weight of English libel law, which places a heavy burden of proof on those making allegations, rather than on the subjects of the allegations who choose to sue, as generally applies in the United States. We will review our approach after a few months.

Meanwhile, we welcome all our readers' contributions to the conversation. 